\title{
Resource orchestration to improve communication with customers: "case study: MSME footwear in East Java"
}

\author{
Juliani Dyah Trisnawati \& Muhammad Rosiawan \\ University of Surabaya, Surabaya, Indonesia
}

\begin{abstract}
This study aims to discuss the orchestration of resources in MSME in accordance with the implementation of ISO 9001 standards and the improvement of product competitiveness. By using case study research approach at MSME footwear in East Java, the results obtained are the information on how the company is orchestrating its resources from the early stages toward the growth stage by means of the certification program of ISO 9001. In the early stages, the company owner has lots of activity of routine work and is only reactive to the problems occurred, but after applying ISO 9001, the owner finds that the management of the company is more coordinated, and controlled. Besides, the company has more activities to develop including establishing communication and maintaining relationships with the customers.
\end{abstract}

Keywords: resource orchestration, ISO 9001 standards, customer communication

\section{INTRODUCTION}

In an effort to face the global market, especially in ASEAN Economic Society (AEC), a company needs to improve its competitiveness and performance. One of the strategies is through the application of a standard quality management system like ISO 9001. This kind of standard helps the company manage the activities and processes systematically, and the result can be better measured (Psomas \& Pantouvakis 2015). Besides, ISO 9001 standard focuses on customer requirements and customer satisfaction, so this kind of standard can be used to improve communication with the customers.

The role of the leaders in managing the resources, involving the staffs in achieving the organization's goal, communicating customer's requirements, focusing on quality is very important in the success of the application of the ISO 9001 standard. This role of the leaders Sirmon et al. (2008) calls as resource orchestration is the role of the leaders in choosing and integrating the resources, and distributing the resources in order to achieve the organization's goal. Because of the rapidly changing business environment, the company's assets such as the organizational asset (governance) capacity is also increased through the application of ISO 9001 standard in or- der to strengthen the company in seizing the opportunities and facing the existing threats.

A number of researches related to the resource orchestration have been conducted, such as Ketchen et al. (2000) who discussed the resource orchestration in the supply chain management (Relational/Customer Capital), resource orchestration research in a family business that requires the importance of skills in entrepreneurship, improvement of participation and involvement in the family generation in running the company (Human Capital) (Chirico et al. 2011), resource orchestration in a video game company in creating values (Structural/Organizational Capital) (Gidhagen et al. 2011), and a research on CEO commitment based resource orchestration in several industries, and the importance of the roles in middle level management in operating company's strategic management (Human Capital) (Chandwick et al. 2014). However, most of the researches on resource orchestration mentioned above were applied to big companies and not in terms of ISO 9001 standard application. This research discusses the resource orchestration in MicroSmall-Medium Scale Enterprise (MSME) footwear in Sidoarjo Regency which is and keeps applying ISO 9001 standard in order to improve the communication with the customers. 
The action of the MSME leaders in realizing the company's competitive advantages through the increase of resource capacity owned depends on the company's lifecycle phase (Ndofor et al. 2014). For example, in the start-up stage and in improving sustainability in the market, the leaders identify, collect, and obtain resources in order to get legitimation (Fitsimmons 2011). Legitimation is obtained when the company is able to adjust with the rules, regulations, and values of the customers. In the start-up stage, the leaders focus on the implementation of resource orchestration for company's operations in achieving growth. In the growth stage, every action from the leaders may require some forms of governance to control the company (Sirmon et al. 2011).

In the start-up stage, the actions of the leaders focus on the resource portfolio arrangement as the foundation of bundling or combining resources in order to form a business model capability that will be used by the company. In the growth stage, the leaders need the ability to manage the structure of the organization effectively to cover the weakness or deficiencies in the growth stage. Moreover, in the growth stage, the leaders have the chance to improve the skills in accessing and developing a relationship with the customers, suppliers, and company's association that play the part in the growth of the company. In general, a growing company has made it possible to mobilize and improve the portfolio which helps in creating competitive advantages. Therefore, ISO 9001 standard is necessary for the MSME owners to move on to the growing stage, so the problems in the form of routines can be controlled through good company governance by adopting the quality management system ISO 9001:2008. Afterwards, in order to speed up the growing stage, MSME leaders can provide the time to improve communication with the customers and the customer satisfaction.

By applying the ISO 9001 standard, the MSME leaders can perform a better governance structure in managing and maintaining the growth and arranging the resources in order to achieve efficiency balance and focus on the needs and expectations of the customers (Sirmon et al. 2011).

\subsection{Research purpose}

This purpose of this case study is to discuss resource orchestration to improve effective communication in MSME footwear in East Java in relation to the application of ISO 9001:2008 SNI standard. It is expected that the practice of ISO 9001, through the compliance of ISO 9001 standard especially on the requirements on customer communication, will improve the company's performance through the ful- fillment of the customers' needs and expectations, complain management, and customer satisfaction.

\section{RESEARCH METHODS}

The approach used in this study was a single case study (Shah \& Corley 2006). The case selected for the study was the MSME which produces footwear namely CV Carita Niaga Sidoarjo. The data collection method was in the form of a semi-structured interview with the owner and the operations manager as the key informant, related document analysis, and observation in the company (Table 1.). The in-depth interview was conducted five times, and each interview lasted for two hours. It was not possible to perform a long period interview because it would disrupt the owner's and operational manager's activities in running the company since they were actively involved in the daily operation assisted by several staffs.

Table 1. Research scope.

\begin{tabular}{lllll}
\hline Case & $\begin{array}{l}\text { Research } \\
\text { Description }\end{array}$ & $\begin{array}{l}\text { Data } \\
\text { Problem }\end{array}$ & $\begin{array}{l}\text { Investi- } \\
\text { resource }\end{array}$ & Output \\
\hline $\begin{array}{l}\text { One MSME } \\
\text { footwear }\end{array}$ & $\begin{array}{l}\text { Resource } \\
\text { orchestra- } \\
\text { tion }\end{array}$ & $\begin{array}{lll}\text { interview } \\
\text { archive } \\
\text { document } \\
\text { observation }\end{array}$ & Single & $\begin{array}{l}\text { Propo- } \\
\text { sition } \\
\text { and } \\
\text { model }\end{array}$ \\
\hline
\end{tabular}

The semi-structured interview was guided by the interview protocol related to the questions on the orchestration of the application of 8 quality management principles to observe the practice of ISO 9001:2008 requirements such as (a) customer focus, (b) leadership, (c) involvement of people, (d) process approach, (e) system approach to management, (f) factual approach to decision making, (g) continual improvement, and (h) mutual beneficial relationship with supplier. The interview was recorded, transcribed, and analyzed using open coding, axial coding, and selective coding (Corbin \& Strauss 1990, Gioia et al. 2012). Open coding was used to identify the concept and grouping the data into categories. Then, axial coding would help find the relation between the category and the subcategory. Finally, selective coding would find the interaction between components.

In order to improve the validity of the result of the case study, this research has to fulfill the principle of research trustworthiness that includes the following four criteria: (1) credibility (using data source triangulation, investigator triangulation, theory triangulation, and method triangulation), (2) transferability (detailed records that illustrate the context of the research) (3) dependability (collecting data up to the saturation condition to get a consistent 
result), and (4) confirm ability (interview result was recorded and transcribed to avoid the researcher's bias (Shah \& Corley 2006, Frambach et al. 2013).

\section{RESULT AND DISCUSSION}

It The result of the identification and analysis of the MSME footwear in Sidoarjo Regency shows that on the startup stage, the company has owned its business permit and its own brand. The growth of the business was quite good seen from the number of staffs and the sales turnover which was increasing each year. However, based on the result of the interview transcript coding, the company's documents, and observation, there are several findings that can be explained as follows: first, In general, the company owner who also acted as the leader of the company has performed a resource orchestration which was good enough in selecting, integrating and resource management for the company's goal. However, the leader of the company still dominated the job functions which are tactical and operational. For the strategic jobs such as market development and relationship building with the actual or potential customers were not yet performed.

Second, the company governance was not yet based on the process and system approach. It was seen through the staffs that were still reactive instead of proactive which the characteristic of a process or system approach is. There has not been good quality management system documentation. Third, the practice of quality management system on customer focus was still quite weak in the planning process in fulfilling the customers' needs, expectations, and satisfaction. Therefore, the control of the production process was also weak. It can be seen by the missing systematic mechanism in the quality control of process and product. Other than the well-calibrated measurement tool, the machine maintenance was well performed. Forth, the practice of quality management principle on factual approach to decision making was still weak. They have not determined the importance of measuring customer satisfaction, internal quality audit, defect product management, data analysis, correction and corrective actions of the nonconformities, and the continuous improvement program.

Based on the inadequacies, the leaders felt the need to improve the company governance. Thus, when there was an offer from National Standardization Body (BSN) who appointed the University of Surabaya (Ubaya) to do mentoring for ISO
9001:2008 certification of MSME in East Java Province, the owner of the company enthusiastically accepted the offer. For about 6 months, the company owner has conducted a continuous socialization process to the staffs and employees on the application of ISO 9001:2008. As a new system, the company leader has to communicate clearly and precisely to the entire staffs. This communication factor is very important in performing a change towards a new system so that the staffs will not be stressed out facing the new and uncertain change (Appelbaum et al. 2000). The eight quality management principles as the foundation of the application of ISO 9001:2008 standard has been applied gradually and increasingly from time to time until it is decided by the BSN team that the company is ready for the certification process by the third party (certification body). After the corrective action of the audit result, the company will be declared ready for certification which shows that the standard requirements of ISO 9001:2008 has been achieved effectively including the interview while the company was still in the startup stage.

Based on the result of the interview, in the growth stage, after achieving the ISO 9001:2008 certification, there is a shift of work orientation of the company owner, from the routines in tactical and operational to the strategic level thinking about creating a new market by doing intensive approach to the potential customers. Moreover, in order to ensure the availability of raw materials, the company owner also communicates and establishes a relationship with the suppliers. Internal resource orchestration is also performed by communicating effectively to the entire staffs to focus on the application of the eight quality management principles. Figure 1 shows the relation of the leaders in orchestrating the resources internally by encouraging the involvement of the staffs in fulfilling the requirements and satisfaction of customer (customer focus). Moreover, the role of the leader is also important in communicating to the entire staffs on the importance of decision making based on facts, doing process approach in routine works, and manages the process interaction as an integrated system to achieve the company's goal. Leaders will also have external functions in encouraging the staffs to communicate with the customers and suppliers. The most important thing is that quality management principles must be improved in order to achieve a better competitiveness and performance. 


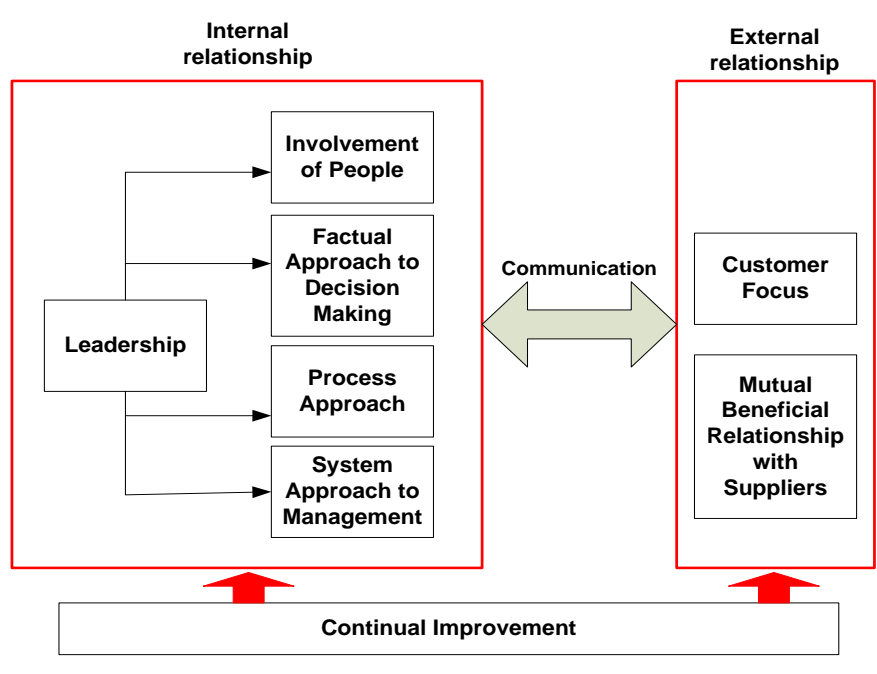

Figure 1. The relation of leadership in improving communication internally or externally based on the eight principles of ISO 9001:2008 quality management.

\section{CONCLUSIONS}

The result of the research is beneficial for the owner of MSME by showing that the application and certification of ISO 9001:2008 standard will make it easier for the owner in orchestrating the resources through the practice of eight principles of quality management principles. The most important factor in the application of resource orchestration is the communication factor, which means that the leader.

\section{REFERENCES}

Appelbaum, S.H., Lefrancois, F., Tonna, R., \& Shapiro, B.T. 2007. Mergers 101 (part two): training managers for culture, stress, and change challenges. Industrial and Commercial Training 39(4): 191-200.

Chandwick, C., Super, J.F., \& Kwon, K. 2014. Resource orchestration in practice: CEO emphasis on SHRM, commitment-based HR system, and firm performance. Strategic Management Journal.

Chirico, F., Sirmon, D., Sciascia, S., \& Mazzola, P. 2011. Resource orchestration in family firms: Investigating how entrepreneurial orientation, generational involvement, and participative strategy affect performance. Strategic Entrepreneurship Journal 5(4): 307-326 URL: http://dx.doi.org/10.1002/sej.121

Corbin, J. \& Strauss, A. 1990. Grounded theory research: procedures, canons, and evaluative criteria. Qualitative Sociology 13: 3-21.

Fitsimmons, G. 2011. Resource management: materials, equipment, facilities. The Bottom Line 22(3): 86-88.

Frambach, J.M., van der Vleuten, P.M. Cees, \& Steven, J. D. 2013. AM last page: quality criteria in qualitative and quantitative research. Academic Medicine 88(4).

Gidhagen, M., Ridell, O. P. \& So“rhammar, D. 2011. The orchestrating firm: value creation in the video game industry. Managing Service Quality 21(4): 392-409. Emerald Group
Publishing Limited 0960-4529 DOI 10.1108/09604521111146261

Gioia, D.A., Corley, K.G., \& Hamilton, A.L. 2012. Seeking qualitative rigor in inductive research: notes on the Gioia methodology. Organizational Research Methods 16(1): 1531.

Ketchen, D.J., Wowak, K.D., \& Craighead, C.W. 2000. Resource gaps and resource orchestration shortfalls in supply chain management: the case of product recalls. Resource Gaps and Resource Orchestration Consumers 50(3): 6-15.

Ndofor, H.A., Sirmon, D.G., \& He, X. 2014. Utilizing the firm's resource: how TMT heterogeneity and resulting fault lines affect TMT tasks. Strategic Management Journal 20.

Psomas, E \& Pantouvakis, A. 2015. ISO 9001 overall performance dimensions: an exploratory study. The TQM Journal 27(5): 519-531.

Shah, S.K. \& Corley, K.G. 2006. Building better theory by bridging the quantitative - qualitative divide. Journal of Management Studies 43(8): 1821-1835.

Sirmon, D.G., Gove, T., \& Hitt, M.A. 2008. Resource management in dyadic competitive rivalry: the effects of resource bundling and deployment. Academic of Management Journal 51(5): 919-935.

Sirmon, D.G., Hitt, M.A., Ireland, R.D., \& Gilbert, B.A. 2011. Resource orchestration to create competitive advantage: breadth, depth, and life cycle effects. Journal of Management 37(5): 1390-1412. 